\title{
Extracorporeal membrane oxygenation in aluminum phosphide poisoning in Nepal: a case report
}

\author{
Achyut Sharma $^{1 *} \mathbb{D}$, Apurb Sharma ${ }^{1}$, Anil Acharya ${ }^{2}$, Diptesh Aryal ${ }^{1}$, Bijoy G. Rajbanshi ${ }^{2}$, Prajjwal Raj Bhattarai ${ }^{1}$, \\ Ashim Regmi ${ }^{1}$ and Anup Ghimire ${ }^{1}$
}

\begin{abstract}
Background: Aluminum phosphide is a very common suicide agent in developing countries like Nepal. Due to the unavailability of a specific antidote, mortality is very high because the phosphine molecule that is formed leads to inhibition of the cytochrome oxidase enzyme system in mitochondria. Extracorporeal membrane oxygenation provides life-saving support to the cardiovascular and respiratory systems until the deadly poison is eliminated from the body.

Case presentation: We encountered one case of 67-year-old Asian woman, a known case of major depressive disorder, who presented to our center with suicidal ingestion of aluminum phosphide with cardiovascular and respiratory dysfunction. On presentation in our emergency room, she had an ejection fraction of 20\% and had to be immediately intubated for respiratory failure. Based on the evidence of almost 100\% mortality with aluminum phosphide poisoning, extracorporeal membrane oxygenation was initiated in our intensive care unit. Her general condition and hemodynamics gradually improved over the course of 2 days and she was weaned from extracorporeal membrane oxygenation and ventilator by post-extracorporeal membrane oxygenation days 3 and 4 , respectively. After psychiatric evaluation and establishment of normal vital parameters, she was moved out of intensive care unit on post-extracorporeal membrane oxygenation day 6 and discharged to home on postextracorporeal membrane oxygenation day 10.
\end{abstract}

Conclusions: Although this seems to be a small step in terms of global perspective, it is a giant stride for a developing country. The management of reversible but severe cardiac and respiratory failure certainly opens up newer scopes where we can ensure a quality health care service being made accessible even to the most underprivileged people.

Keywords: ECMO, Extracorporeal membrane oxygenator, Aluminum phosphide poisoning, Poisoning in Nepal, Veno-arterial ECMO

\section{Background}

Aluminum phosphide (AlP) ingestion or inhalation by accident or with suicidal intent is one of the commonest modes of poisoning in Nepal $[1,2]$. This lethal form of poisoning has no specific antidote and has a mortality rate as high as 45 to $100 \%$ [3, 4]. Although a majority of patients may remain asymptomatic or have mild

\footnotetext{
* Correspondence: achyutsharma@gmail.com

${ }^{1}$ Department of Anaesthesia, Pain Management, and Critical Care, Nepal

Mediciti Hospital, Nakhkhu Patan, Karyabinayak 44600, Nepal

Full list of author information is available at the end of the article
}

symptoms of nausea and vomiting on initial presentation, there is rapid deterioration in clinical condition mainly due to cardiac and respiratory failure. The formation of phosphine $\left(\mathrm{PH}_{3}\right)$ gas when AlP interacts with moisture in the environment or acid in the stomach causes a cyanide-like toxicity in which mitochondria are unable to utilize oxygen due to the inhibition of the cytochrome oxidase enzyme system. The resultant anaerobic metabolism and severe lactic acidosis causes multiorgan dysfunction and death ensues rapidly. A variety of supportive measures in the form of rapid and

(c) The Author(s). 2018 Open Access This article is distributed under the terms of the Creative Commons Attribution 4.0 International License (http://creativecommons.org/licenses/by/4.0/), which permits unrestricted use, distribution, and 
prompt lavage with potassium permanganate, use of activated charcoal to delay absorption, magnesium sulfate, vegetable oils, coconut oil $[5,6]$, and so on have been tried with mixed results. A therapy that provides astounding support to the organ system until the dreaded poison is eliminated via the kidneys is extracorporeal membrane oxygenation (ECMO); ECMO has shown consistently positive results in the management of AlP poisoning in several countries. Although ECMO has been used in Nepal previously [7], this case report describes probably the first use of ECMO in an A1P case in Nepal. This case opens up a whole new horizon in the management of one of the commonest causes of fatal rodenticide poisoning in south asia.

\section{Case presentation}

A 67-year-old Asian woman with a known long history of major depressive disorder was brought to our emergency room (ER) with complaints of intentional ingestion of two tablets of AlP 5 hours prior to presentation. Except for the depressive illness for which she was taking a tablet form of escitalopram $20 \mathrm{mg}$ twice daily, with which she was compliant, there was no other significant medical, surgical, or family history. She was seen by her son who found her in her room complaining of nausea and vomiting when she expressed to him about her ingesting the tablets. She had multiple episodes of vomiting containing greenish-colored particulate material which was not blood mixed. She also had three episodes of loose stools and generalized body weakness with altered sensorium. Before she was brought to our $E R$, she was taken to another center where she was primarily managed with gastric lavage and initial resuscitation. When she was evaluated in our ER, she was drowsy, her Glasgow Coma Scale (GCS) was 8/15, and her pupils were bilaterally $4 \mathrm{~mm}$ and sluggish reactive to light. Her pulse was $58 /$ minute, she had blood pressure (BP) of $80 / 60 \mathrm{mmHg}$, her respiratory rate (RR) was $35 /$ minute, and arterial oxygen saturation was $93 \%$ with supplemental oxygen via face mask. On auscultation, there were crepitations bilaterally along with decreased breath sounds. An initial arterial blood gas (ABG) done in ER revealed $\mathrm{pH}$ of 7.094, partial pressure of oxygen in blood $\left(\mathrm{PaO}_{2}\right) 130 \mathrm{mmHg}$, partial pressure of carbon dioxide in blood $\left(\mathrm{PaCO}_{2}\right) \quad 23.5 \mathrm{mmHg}$, bicarbonate $\left(\mathrm{HCO}_{3}\right) 8.9 \mathrm{mmHg}$, and serum lactate of 15 .

Besides these clinical findings and laboratory parameters other tests were within normal range. A chest X-ray was done immediately, which showed infiltrations with bilateral opacities. A 12-lead electrocardiogram (ECG) showed sinus rhythm, non-specific ST-T changes in all leads. Cardiologists were immediately called for screening echocardiographic evaluation which showed significantly reduced systolic function of left ventricle with an ejection fraction (LVEF) of $20 \%$. While evaluation was ongoing, a wide bore canula was opened, and dopamine was started to support the blood pressure. However, patient's condition continued to deteriorate and an immediate plan for veno-arterial ECMO was made. After obtaining consent for ECMO from patient's son, the intensive care unit (ICU) team was alerted and cardiac surgeons were informed accordingly. The patient was successfully connected to ECMO (Sorin SCPC Centrifugal Pump System) via right femoral vein and femoral artery. An extra 6F sheath was inserted distally into femoral artery for perfusion of distal leg.

In the immediate postoperative period the patient was kept on mechanical ventilator volume assist-control mode on low tidal volume lung protective ventilation at $40 \%$ fraction of inspired oxygen concentration $\left(\mathrm{FiO}_{2}\right)$ with positive end-expiratory pressure (PEEP) of $7 \mathrm{cmH}_{2} \mathrm{O}$. We were able to deliver an almost constant flow of $3 \mathrm{~L} /$ minute $/ \mathrm{m}^{2}$ on ECMO and provided oxygenation at $\mathrm{FiO}_{2}$ of $70 \%$. She was also kept on epinephrine, norepinephrine support, magnesium sulfate, vitamin C, thiamine, hydrocortisone, heparin infusion, and sodium bicarbonate therapy. An ABG done immediately after the procedure showed improvement in acid-base status as well as decrease in lactate level to 0.31 . Blood gases were repeated 4 hourly. Boluses of heparin 1000-3000 U were given along with adjustment in background infusion rate to keep the activated clotting time (ACT) between 180 and 220 seconds.

An echocardiography done the next day showed significant improvement in cardiac status with LVEF reaching 35\%. Her general condition, consciousness level, hemodynamic stability, and ventilatory parameters, especially peak airway pressure, also showed significant improvement over the next 3 days and we were able to stop all inotropic supports by ECMO day 2. She was finally weaned off the ECMO on day 3 and extubated the next day. At all times during her stay in ICU, although she showed signs of myocardial dysfunction and respiratory failure along with depression of mental status, her renal and liver function tests remained within normal range. A psychiatric evaluation was done while she was in ICU. After observation in ICU for 2 more days, she was discharged to ward with stable vital signs. She stayed in wards for 4 more days and was then finally discharged to home to have follow-up later and scheduled psychiatric consultation and adjustment of medications accordingly (timeline; Fig. 1).

\section{Discussion}

A1P is a common suicide agent especially in countries like Nepal, India, and Iran [2-4]. Used for various domestic and agricultural purposes, this agent is readily available in the market. Accidental inhalation of A1P in 


\section{Timeline of Events}

\section{Major depressive disorder under regular} Escitalopram tablet $20 \mathrm{mg}$ daily.

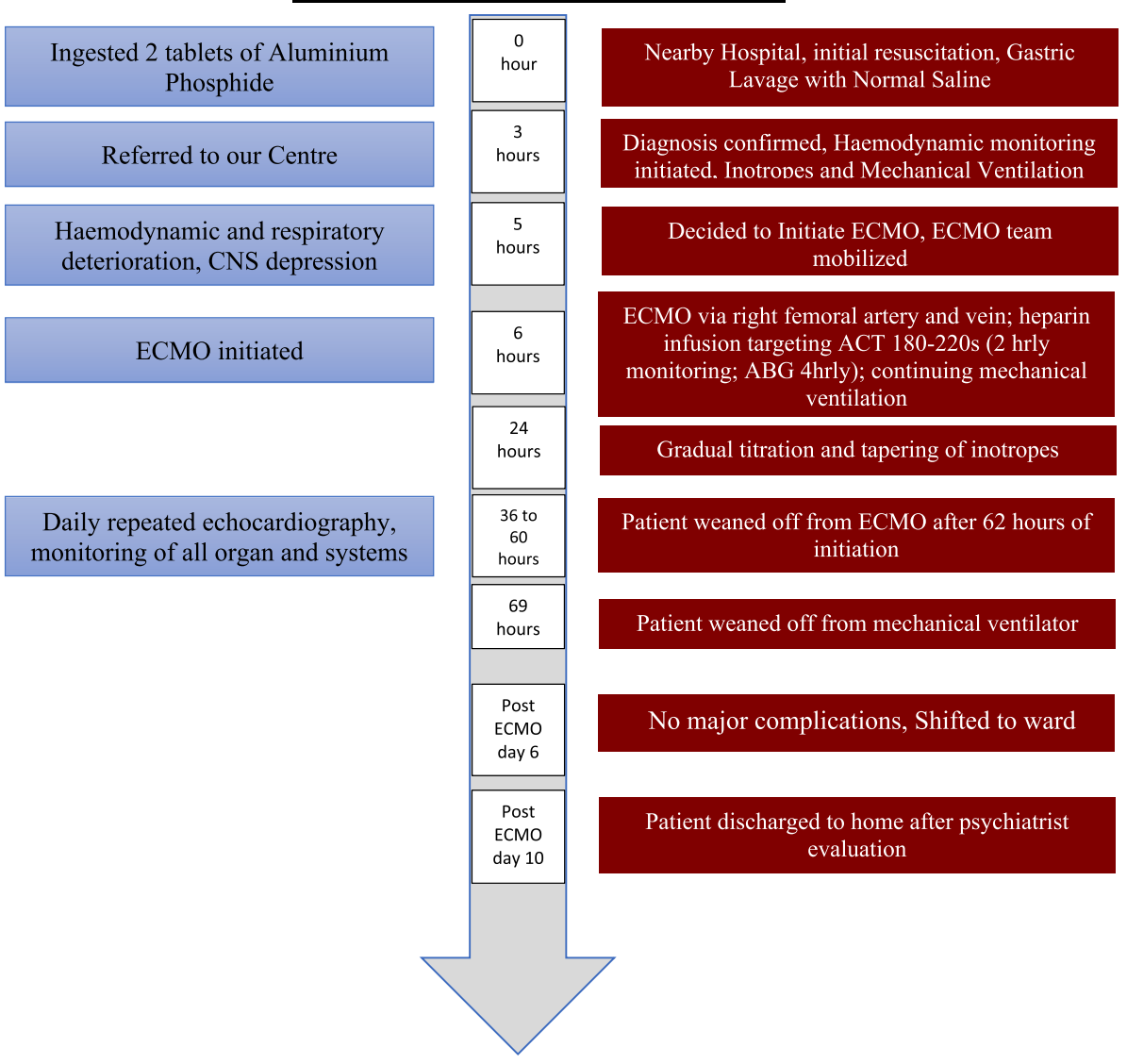

Successful treatment of aluminium phosphide poisoning

Fig. 1 Timeline. CNS central nervous system, ECMO extracorporeal membrane oxygenation

fields and often suicidal ingestion of this agent by persons who are depressed or suffering from psychiatric illnesses [8] result in rapid deterioration in organ function. The deadly $\mathrm{PH}_{3}$ gas that is generated as a result of its interaction with environmental moisture or acid in the stomach results in inhibition of the cytochrome oxidase enzyme system in mitochondria due to which the body is unable to utilize oxygen for aerobic metabolism [9]. The ultimate dependence on anaerobic metabolism results in significant lactate accumulation and severe metabolic acidosis. In the major organ systems, myocardial dysfunction and respiratory failure lead to hypotension, hypoxemia, and ultimately death. Due to the unavailability of specific antidotes, several agents have been tried but none have been effective in its management and the mortality rate remains as high as $80-90 \%$ [10], although it varies depending on the amount consumed or inhaled. The only consistently promising treatment option for this poisoning has been ECMO. In this therapy, a "time-buy" approach is utilized in which the cardiovascular and respiratory systems are supported until the poison is eliminated from the body mainly by the kidneys. This approach to AlP poisoning is so effective that in one study from India, the clinicians were able to reduce the mortality rate from $88 \%$ in untreated cases to $33 \%$ when ECMO was used [11].

The significant difference in the management of AlP poisoning with ECMO in our case was its relatively early initialization before trying other treatment options. Due to the sheer amount of risk involved with ECMO, the usual practice of resorting to ECMO as an ultimate therapy when other therapies fail is common. However, deviation from that norm was necessary in our case for 
some specific reasons. First, unlike other cases of rodenticide poisoning where the population group is relatively young with healthy organ systems, our patient was a sexagenarian and did not have a good physiologic reserve and it was necessary to support her early given that her baseline echocardiography was not good. Second, as our center is well equipped with cardiovascular and good critical care unit backup, we were comfortable enough to start the therapy within a short period of time which ultimately would have helped our patient with much needed support. However, during the course of treatment the most pertinent question that we often asked ourselves and sought to find the answer to was: How long should we run ECMO? There is no definite answer to this question, however. Since the use of ECMO is indicated mostly for reversible pathologies, the assurance of the treatment of the primary pathology is probably the most important time when ECMO can be stopped. In our case, for example, the time taken for the poison to be eliminated from our patient's body was the most appropriate time for weaning her off of ECMO. However, this cannot be objectively determined. Therefore, we resorted to methods of indirect tests such as daily echocardiography screening, chest $\mathrm{X}$-rays, and daily physical examination including assessment of our patient's consciousness level to determine the appropriate time for weaning off of ECMO. To the best of our knowledge, there are no set criteria or guidelines to guide us in this process and this weaning process remains at the discretion of the treating physicians.

The use of ECMO, however, is not only limited to poisoning. Veno-venous ECMO is designed to provide respiratory support especially in conditions like acute respiratory distress syndrome (ARDS)-associated refractory hypoxemia. In this technique, blood is removed from the venous side and pumped back into it, however, this does not provide hemodynamic support. In veno-arterial ECMO, blood is pumped from the venous side to the arterial side. In the process of doing this, it provides both gas exchange as well hemodynamic support [12]. The setup, however, for both these types of ECMO is similar. Blood movement across the circuit and into the patient's large vessels is made possible by an external pump that forces the blood through a membrane oxygenator allowing gas exchange and carbon dioxide $\left(\mathrm{CO}_{2}\right)$ removal in the process. Although the benefits of ECMO far outweigh the complications like hemorrhage and infection, with which it is most commonly associated, a consultation with an ECMO specialist or perfusionist is mandatory as the operation of these devices varies considerably across different models.

\section{Conclusions}

Although the use of ECMO in AlP poisoning in other parts of the world is not new, this is a new experiment for us. Despite its availability, ECMO was never used for this purpose before in Nepal which we believe was due to hesitation because of fear about its success. In a country where considerable numbers of people die each year simply because of the result of their momentary decision to end their lives and who, otherwise, would have lived a productive life, there seems to be a possibility to reverse those reversible changes; this success surely opens doors to more opportunities. This simple yet novel approach to AlP treatment success in our center will certainly provide a much needed impetus to the flourishing of such uses in other centers as well and we hope to see many more lives saved in this mountainous country.

\section{Abbreviations}

ABG: Arterial blood gas; ACT: Activated clotting time; AIP: Aluminum phosphide; ARDS: Acute respiratory distress syndrome; BP: Blood pressure; $\mathrm{CO}_{2}$ : Carbon dioxide; ECG: Electrocardiogram; ECMO: Extracorporeal membrane oxygenation; ER: Emergency room; $\mathrm{FiO}_{2}$ : Fraction of inspired oxygen concentration; GCS: Glasgow Coma Scale; $\mathrm{HCO}_{3}$ : Bicarbonate; ICU: Intensive care unit; LVEF: Left ventricular ejection fraction; $\mathrm{PaCO}_{2}$ : Partial pressure of carbon dioxide in blood; $\mathrm{PaO}_{2}$ : Partial pressure of oxygen in blood; PEEP: Positive end-expiratory pressure; $\mathrm{PH}_{3}$ : Phosphine; RR: Respiratory rate

\section{Acknowledgements \\ Dr Lava N. Joshi, MD \\ Dr Hemant Adhikari, MD \\ Dr Shikchya Khatiwada, MD \\ Dr Diwas Manandhar, MD}

\section{Availability of data and materials}

The relevant laboratory investigations are available in electronic medical records of the hospital and can be accessed if required.

\section{Authors' contributions}

AcS primary author, actively involved in the management of the case, and drafting, reviewing, editing, preparing, and final approval of the manuscript. ApS, AA, DA, BGR, PRB, AR, and AG involved directly in patient management, reviewing, and final approval of the manuscript.

Ethics approval and consent to participate

Ours is a retrospective report of a successful management of A1P poisoning. Thus ethical approval and consent to participate are not relevant.

\section{Consent for publication}

Written informed consent was obtained from the patient's legal guardian for publication of this case report and the accompanying timeline. A copy of the written consent is available for review by the Editor-in-Chief of this journal.

\section{Competing interests}

The authors declare that they have no competing interests.

\section{Publisher's Note}

Springer Nature remains neutral with regard to jurisdictional claims in published maps and institutional affiliations.

\section{Author details}

'Department of Anaesthesia, Pain Management, and Critical Care, Nepal Mediciti Hospital, Nakhkhu Patan, Karyabinayak 44600, Nepal. ${ }^{2}$ Department of Cardiothoracic and Vascular Surgery, Nepal Mediciti Hospital, Nakhkhu Patan, Karyabinayak 44600, Nepal. 
Received: 3 July 2018 Accepted: 1 October 2018

Published online: 28 October 2018

\section{References}

1. Gyenwali D, Vaidya A, Tiwari S, Khatiwada P, Lamsal DR, Giri S. Pesticide poisoning in Chitwan, Nepal: a descriptive epidemiological study. BMC Public Health. 2017;17(1):619.

2. Shrestha B, Singh PM, Bharati U, Dhungel S. Poisonings at Nepal Medical College Teaching Hospital. Nepal Med Coll J. 2011;13(3):199-204.

3. Hassanian-Moghaddam H, Zamani N, Rahimi M, Hajesmaeili M, Taherkhani M, Sadeghi R. Successful Treatment of Aluminium Phosphide Poisoning by Extracorporeal Membrane Oxygenation. Basic Clin Pharmacol Toxicol. 2016; 118(3):243-6.

4. Neki NS, Shergill GS, Singh A, Kaur A, Nizami S, Singh T, et al. Recent Advances in Management of Aluminium Phosphide Poisoning. Int J Curr Res Med Sci Updat Artic. 2017;3(3):73-6

5. Farahani MV, Soroosh D, Marashi SM. Thoughts on the current management of acute aluminum phosphide toxicity and proposals for therapy: An Evidence-based review. Indian J Crit Care Med. 2016;20(12):724-30.

6. Gurjar M, Azim A, Baronia A, Sharma K. Managing aluminum phosphide poisonings. J Emerg Trauma Shock. 2011;4(3):378.

7. Sharma A, Pokharel JN, Upreti MR, Koirala B, Sharma J, Pradhan S, Bhatta M. Initial experience with extracorporeal membrane oxygenation following cardiac surgery in children with congenital heart disease. Nepal Heart J. 2014;11(1):39-44.

8. Etemadi-Aleagha A, Akhgari M, Iravani FS. Aluminum Phosphide PoisoningRelated Deaths in Tehran, Iran, 2006 to 2013. Medicine (Baltimore). 2015; 94(38):e1637.

9. Moghadamnia A. An update on toxicology of aluminum phosphide. DARU J Pharm Sci. 2012;20(1):25.

10. Siwach SB, Gupta A. The profile of acute poisonings in Harayana-Rohtak Study. J Assoc Physicians India. 1995;43(11):756-9.

11. Mohan B, Gupta V, Ralhan S, Gupta D, Puri S, Wander GS, et al. Role of Extracorporeal Membrane Oxygenation in Aluminum Phosphide PoisoningInduced Reversible Myocardial Dysfunction: A Novel Therapeutic Modality. J Emerg Med. 2015;49(5):651-6.

12. Martinez G, Vuylsteke A. Extracorporeal membrane oxygenation in adults. Contin Educ Anaesth Crit Care Pain. 2012;12(2):57-61.

Ready to submit your research? Choose BMC and benefit from:

- fast, convenient online submission

- thorough peer review by experienced researchers in your field

- rapid publication on acceptance

- support for research data, including large and complex data types

- gold Open Access which fosters wider collaboration and increased citations

- maximum visibility for your research: over $100 \mathrm{M}$ website views per year

At $\mathrm{BMC}$, research is always in progress.

Learn more biomedcentral.com/submissions 